Mentalizing mediates the relation between childhood maltreatment and adolescent borderline and narcissistic personality traits

Josée Duval, Karin Ensink, Lina Normandin \& Peter Fonagy 


\begin{abstract}
Background: Childhood maltreatment is theorized to undermine the development of mentalizing and to disrupt the development of healthy narcissism and the integration of personality at the level of affect and interpersonal regulation. Consistent with this, mentalizing can be expected to mediate the relationship between childhood maltreatment and vulnerable and grandiose narcissism as well as borderline personality triats, but this has not been examined in adolescents.
\end{abstract}

Objective: The aim of this study was to examine associations between childhood maltreatment and adolescent personality disorder traits and test the mediating role of mentalizing in a sample of 263 adolescents and young adults aged 12 to 21 .

Method: Participant recruited from school and a tertiary institution completed the Childhood Experiences of Care and Abuse Questionnaire (CECA-Q), the Borderline Personality Disorders Features Scale (BPFS-C), the Pathological Narcissism Inventory (PNI) and the Reflective Function Questionnaire for Youth (RFQ-Y).

Results: Adolescents with histories of sexual and physical abuse reported significantly more borderline personality features, as well as vulnerable and grandiose narcissism. They also reported signficantly more mentalizing difficulties including confusion regarding mental states and excessive certainty regarding mental states of others. Confusion regarding mental states partially mediated the relation between emotional abuse and borderline personality traits, as well as vulnerable and grandiose narcissism. Excessive certainty regarding the mental states of others mediated the relationship between childhood experiences of role reversal and grandiose narcissism. 
Conclusion: The findings are consistent with a mentalization model of adolescent personality difficulties and show that the relation between childhood maltreatment and personality disorder traits in adolescents may be in part be understood in terms of the impact of such experiences on different dimensions of mentalizing.

Keywords: mentalizing, adolescents, maltreatment, Borderline Personality Disorders, Narcissistic Personality Disorders 


\section{Mentalizing mediates the relation between childhood maltreatment and adolescent borderline and narcissistic personality traits}

There has been an upsurge in interest in Borderline Personality Disorder in adolescents with evidence that it can be reliably diagnosed (Glenn \& Klonsky, 2013; Michonski, Sharp, Steinberg \& Zanarini, 2013), affects a sizable percentage of adolescents (Miller, Muehlenkamp \& Jacobson, 2008) and is associated with marked dysfunction in terms of self and interpersonal functioning (Glenn \& Klonsky, 2013; Winsper et al., 2015). There is also growing interest in pathological narcissism in adolescents, but to date this remains under researched. There is evidence suggesting that childhood maltreatment is a risk factor for the development of borderline traits in school-aged children and adolescents (Bounoua et al., 2015; Jovev et al., 2013; Zelkowitz, Paris, Guzder \& Feldman, 2001), as well as vulnerable and grandiose narcissism in adolescents (Ensink et al., 2017). However, the processes through which maltreatment associates with personality disorder traits in adolescents remain unknown. Mentalization, as conceptualized by Fonagy and colleagues (2002), and operationalized for research purposes as reflective functioning (FR), is considered a potential resilience factor that may mediate the relationship between childhood maltreatment and adolescent personality disorders. Initial evidence suggests that mentalizing is associated with borderline personality disorder in adults (Chiesa \& Fonagy, 2014), as well as with borderline and narcissitic traits in adolescents (Duval, Ensink, Normandin, Sharp \& Fonagy, 2018; Sharp, Penner \& Ensink, under review). Furthermore, mentalizing difficulties has also been shown to be associated with maltreatment and to mediate the relationship between maltreatment and adult BPD (Chiesa \& Fonagy, 2014) and child psychological problems (Ensink, Bégin, Normandin \& Fonagy, 2016). However, the mediating effect of mentalizing between maltreatment and borderline and 
narcissistic personality disorders in adolescents remains to be studied. Against this background, the aims of the present study were to examine possible pathways from early experiences of maltreatment, through different dimensions of mentalizing, to personality disorders in adolescents.

\section{Maltreatment and borderline personality disorder.}

Maltreatment which evokes fear, aggression or where children are left for long periods without help to regulate, is known to undermine the development of regulatory processes. Maltreatment may have permanent negative implications for affect regulation through the negative impact of prolonged exposure to high levels of cortisol on the developing hypothalamicpituitary-adrenal (HPA) axis with long term consequences for the physiological processes associated with stress regulation (Cross, Fani, Powers \& Bradley, 2017). Childhood maltreatment has been identified as a risk factor for BPD in adulthood in community samples (Afifi et al., 2011; Widom, Czaja \& Paris, 2009), as well as in clinical samples (Battle et al., 2004; Chiesa \& Fonagy, 2014; Sansone, Hahn, Dittoe \& Wiederman, 2011). Research on the relationship between maltreatment and BPD in adolescence is more limited, but consistent with the adult literature, there is some evidence that childhood abuse and neglect are risk factors for the development of borderline traits in school-aged children and adolescents (Bounoua et al., 2015; Jovev et al., 2013; Zelkowitz et al., 2001). For example, children who experienced sexual abuse were found to be at a four-fold risk of developing borderline personality traits (Zelkowitz et al., 2001). In addition, adolescents who experienced sexual abuse and parental antipathy in

combination with others forms of maltreatment were found to manifest significantly more borderline personality features (Bégin, Ensink, Chabot, Normandin \& Fonagy, 2017). 
Theoretical and empirical models suggest an interaction between genetic and environmental factors in the etiology of BPD (Bornovalova et al., 2013; Crowell, Kaufman \& Beauchaine, 2014; Joyce et al., 2003; Stepp et al., 2014). Consistent with this, maltreatment (physical and psychological abuse) before the age of 10 has been found to predict borderline personality traits in 12 year olds, but genetic vulnerability (measured by psychiatric antecedents in the family) greatly increased the chances that maltreated children would develop borderline personality traits in adolescence (Belsky et al., 2012). In line with this, temperament, assumed to be genetically based, has been shown to moderate the expression of borderline pathology in adolescents who experienced abuse and neglect (Jovev et al., 2013).

\section{Maltreatment and pathological narcissism.}

There are still important gaps in our knowledge regarding the developmental precursors of grandiose narcissism and vulnerable narcissism (Dickinson \& Pincus, 2003; Miller et al., 2011). Some studies report positive relationships between maltreatment and both grandiose and vulnerable narcissism (Ménard \& Pincus, 2014), while others suggest that parental coldness or intrusive behaviors contribute to the development of vulnerable narcissism, but not grandiose narcissism (Miller et al., 2010). In another study, negative parenting such as inconsistent discipline and lack of supervision was found to be linked to vulnerable narcissism in 16-17 year olds, while grandiose narcissism was associated more with parental investment and unconditional positive reinforcement (Mechanic \& Barry, 2015). Consistent with this, overvaluation, and not lack of warmth and affection, was found to predict grandiose narcissism in children aged 7-12 (Brummelman et al.; 2015). Furthermore, role reversal, or parentification, where the child is forced to adopt parental emotional roles and responsibilities (Haxhe, 2016), has also been linked to narcissism (Jones \& Wells, 1996). 


\section{Mentalizing.}

Mentalizing as conceptualized by Fonagy, Gergely, Jurist and Target (2002) refers to the processes involved in imagining why others behave the way they do, while also being cognizant of our own emotional reactions, their connection to our beliefs and the impact of our mental states on others. Fonagy et al. propose a developmental model whereby children learn about mental states in the context of early attachment relationships where parents interpret and explain children's behavior and that of others as communication about internal states, underlying psychological reactions and emotions. In this process, children learn about their own minds and become aware of their emotions and learn to understand and link their own reactions, as well as that of others, to underlying psychological states and feelings. Fonagy and Alison (2014) describe this process as a natural pedagogy where parents with a mentalizing stance transmit knowledge about minds and a way of thinking and understanding their own reactions and that of others in terms of underlying mental and emotional states. Furthermore, in the context of secure attachment relationships with parents who can be trusted to have a benign interest in their minds, children may likely be more willing to share their preoccupations and explore and mutually elaborate understandings of their difficulties, thus deepening their understanding of themselves as individuals, their behaviors and their minds and facilitating resilience (Ensink, Bégin, Normandin \& Fonagy, 2017).

Mentalizing facilitates interpersonal functioning because understanding the reactions of others and knowing what impact one's own behavior is likely to have on others makes interpersonal reactions predictable. Mentalizing and socio-cognitive capacities are considered to be a resilience factor particularly important for adolescents to successfully engage with the psychosocial challenges endemic to the transition to adulthood (Braehler \& Schwannauer, 2012) 
while mentalizing difficulties contribute to vulnerability to mental health problems in children (Ensink et al., 2016) and adolescents (Duval et al., in press; Ha, Sharp, Ensink, Fonagy \& Cirino, 2013; Sharp et al., under review; Taubner, White, Zimmerman, Fonagy \& Nolte, 2013).

\section{Mentalizing and Maltreatment.}

Maltreatment is theorized to impact the development of mentalizing in multiple ways. In contexts of maltreatment, like neglect or antipathy, children may have little access to relationships of trust in which learning about their own minds and that of others is fostered (Fonagy \& Bateman, 2007). Furthermore, maltreatment by attachment figures who provoke fear is considered to activate hypervigilance and fast reflexive mental processing of external cues developed to detect potential danger, undermining the development of slower reflective processing (Fonagy, 1999). In addition, when the minds of attachment figures sometimes harbor frightening or malevolent intentions, it may be adaptive for children to inhibit their natural curiosity regarding the minds of others (Fonagy,1999). Finally, caregivers who are psychologically abusive and miss-attribute negative intentions to children's behavior, may actively distort and interfere with the development of mentalizing regarding self and others. Consistent with the above, children and adolescents exposed to maltreatment have been shown to manifest deficits in a range of social cognitive abilities including emotion recognition (Koizumi \& Takagishi, 2014; Pears \& Fisher, 2005; Pollak, Cicchetti, Hornung \& Reed, 2000; Shenk, Putnam \& Gold, 2013 ) and theory of mind (Cicchetti, Rogosch, Maughan, Toth \& Bruce, 2003;

O’Reilly \& Peterson, 2015; Pears \& Fisher, 2005). Evidence regarding maltreatment and child and adolescent RF is more limited. Ensink and colleagues (2015) found that children with histories of sexual abuse have lower RF (about self or others) than non-abused children. Moreover, children who experienced intrafamilial sexual abuse had more mentalizing difficulties 
than those who experienced extrafamilial sexual abuse. Furthermore, child mentalization was found to partially mediate the relationship between child sexual abuse and depressive symptoms as well as the relationship between child sexual abuse and externalizing difficulties (Ensink et al., 2016).

Further research is however needed to understand the relationship between different types of maltreatment and different dimensions of mentalizing in adolescents, and the way this may be implicated in risk and resilience for psychological difficulties.

\section{Mentalizing and borderline and narcissistic traits.}

Fonagy and Bateman (2007) theorized that deviations in the normal development of mentalization, associated with difficulties in the parent-child relationship, may contribute to psychopathology in adulthood, including BPD. Consistent with this proposal, Fonagy et al. (1996) found that inpatients with histories of physical or sexual abuse and low RF were more likely to be diagnosed with BPD than inpatients that also have a history of abuse, but a higher RF. Based on this finding, they postulated that RF could be a protective factor for individuals with childhood experiences of abuse. In further support of this assumption, Chiesa and Fonagy (2014) found that RF partially mediated the relationship between childhood adversity and the development of BPD in adulthood.

Studies on mentalizing and pathological narcissism are rare. There is evidence suggesting that narcissism is associated with a tendency to overestimate mentalizing abilities (Ames \& Kammrath, 2004; Ritter et al., 2011) while grandiose narcissism has been specifically associated with excessive certainty about the mental states of others, as measured with the Reflective Function Questionnaire for Youth (RFQ-Y; Duval et al., 2018). 


\section{This study.}

The aim of the study was to investigate associations between maltreatment, different dimensions of mentalizing (measured using a self-report questionnaire), as well as borderline and narcissistic personality traits in adolescence. A further objective was to examine whether RF mediates the relationships between maltreatment and personality disorder traits. We hypothesized that: (1) maltreatment (physical abuse, sexual abuse, emotional abuse and role reversal) would be associated with more borderline personality traits and pathological narcissism, (2) mentalizing difficulties and a lack of interest/curiosity in mental states would be associated with more borderline traits and pathological narcissism, and (3) that maltreatment would be linked to more mentalizing difficulties and less interest/curiosity in mental states. Based on previous findings with children, adolescents and adults (Chiesa \& Fonagy, 2014; Ensink et al., 2016; Taubner \& Curth, 2013), we hypothesized that RF would mediate the relationship between maltreatment and borderline and narcissistic traits in adolescence.

\section{METHOD}

\section{Sample and Participant Selection:}

This study was part of a larger project on personality disorders in adolescence and trauma, mentalization, personality and psychological difficulties. The sample reported in here consisted of a total of 263 participants aged 12 to 21 years old $(M=17,08, E T=4,45)$ who agreed to complete the Childhood Experience of Care and Abuse Questionnaire (CECA.Q ; Bifulco, Bernazzani, Moran \& Jacobs, 2005). Participants were recruited from high schools and a university. The majority of the participants were female, representing approximately $78 \%$ of our sample. The majority of participants identified themselves as Caucasian (92 \%), 1,9\% as Afro- 
American, 1,9\% as Asian, 2,7\% as Hispanic et 1,6\% as other. Descriptive statistics for participants and measures are summarized in Table 1. Adolescents aged 14 years and older consented to participate in the study by signing the paper or electronic consent form. The consent provided by the adolescents was in accordance with Article 21 of the Civil Code of Québec which specifies that from age 14 adolescents have the right to decide to consent to certain activities such as participating in research. For 12- and 13-year-olds, parental consent was required prior to their participation in the study. Once parental consent was received, a link was forwarded by email to the adolescents so they could complete the online questionnaires. The study was approved by the Ethics Committee for Research with Human Subjects of LAVAL University.

\section{Assessments and Measures:}

Pathological Narcissism. This study used the French version of the Pathological Narcissism Inventory (PNI; Pincus et al., 2009) adapted for adolescents (Chrétien, Ensink, Descoteaux, Daigle \& Normandin, submitted). The PNI is a 52-item self-report questionnaire which assesses pathological narcissism, more specifically grandiose narcissism and vulnerable narcissism. It consists of seven scales: 1) contingent self-esteem, 2) exploitative, 3) self-sacrificing selfenhancement, 4) hiding the self, 5) grandiose fantasy, 6) devaluation, and 7) entitlement rage. Answers are indicated along a 6-point Likert scale ranging from $(0)=\mathrm{I}$ am really not like that to (5) $=$ I am very much like that. Mean scores are calculated for each scale. The grandiose narcissism $(a=.86)$ score is calculated by summing and averaging the scores for the exploitative, self-sacrificing self-enhancement and grandiose fantasy scales, while the vulnerable narcissism $(a=.93)$ score is obtained by summing and averaging contingent self-esteem, hiding the self, devaluation, and entitlement rage scale scores. (Wright et al, 2010). The French PNI-A 
has been shown to have a robust factor structure, good test-retest reliability, and good construct validity. In addition, the same two-factor structure representing grandiose and vulnerable narcissism demonstrated to be present for the adult PNI was replicated in the French PNI-A (Chrétien et al., submitted).

Borderline traits. The Borderline Personality Features Scale for Children (BPFS-C) is a 24-item questionnaire which assesses borderline personality traits in children and adolescents age 9 and overt (Crick, Murray-Close \& Woods, 2005). It was adapted from the borderline personality subscale of the Personality Assessment Inventory (PAI; Morey, 1991), a valid and reliable measure of personality pathology (Boone, 1998; De Moor, Distel, Trull, \& Boomsma, 2009; Slavin-Mulford et al., 2012; Stein, Pinsker-Aspen, \& Hilsenroth, 2007). The BPFS-C consits of 4 scales of 6 items: affective instability, identity problems, negative relationships and self-harm. Item responses are indicated along a 5 -point Likert scale ranging from $(1)=$ not at all true to $(5)=$ always true. Scores for four of the six items in each subscale are reversed and a total score ( $a=$ $.91)$ is then calculated by summing the scores for each item. An elevated score is indicative of the presence of several borderline personality traits. The French version used here has been shown to have good internal consistency with a Cronbach alpha of .91 for the total score (Bégin, Leclerc, Thériault-Sereno, Ensink, \& Normandin, submitted).

Reflective functioning (RF). The French version (Duval et al., 2018) of the Reflective Function Questionnaire for Youth (RFQ-Y; Ha et al., 2013) was used to assess RF in adolescents. The selfreport questionnaire consists of 25 items along a 6-point Likert scale ranging from $(1)=$ totally disagree to $(6)=$ totally agree. There are three scales. The first one, uncertainty/confusion $(a=$ .89), contains 11 items that illustrate confusion about mental states or a difficulty in recognizing and distinguishing mental states. The second one, interest/curiosity $(a=.79)$, brings together 8 
items that highlight the individual's interest in mental states as well as his or her ability to become aware of mental states underlying behaviors. The third one, excessive certainty $(a=.82)$, consists of 6 items that show the individual's certainty of his or her knowledge of mental states of others. A mean score is calculated for each scale. The uncertainty/confusion and excessive certainty scales both represent mentalization difficulties whereas the interest/curiosity scale approximates an adequate or optimal mentalization.

Trauma. Childhood abuse and negligence were measured using the French translation of the Childhood Experience of Care and Abuse Questionnaire (CECA.Q; Bifulco, Bernazzani, Moran \& Jacobs, 2005) which examines relationships with attachment figures from 0 to 17 years old. The questionnaire had been adapted from the Childhood Experience of Care and Abuse Interview which validity is well supported in literature (Bifulco et al. 1994). It consists of 6 scales: (1) antipathy ( $a=.86),(2)$ negligence ( $a=.86)$, (3) psychological abuse ( $a=.89)$, (4) physical abuse, (5) sexual abuse and (6) role reversal ( $a=.83$ ). The antipathy scale assesses hostile, cold, rejecting or blaming attitudes from parents (i.e. makes the child a scapegoat for family issues). The neglect scale includes questions that assess the lack of provision of physical, educational, and emotional needs. The physical abuse scale refers to hitting of different intensities and frequencies. The psychological abuse scale assesses threatening or cruel behaviours as well as isolation. Finally, the sexual abuse subscale assesses experiences of sexual contact with an adult, or propositions by them or exposure to situations that are of a sexual nature but excludes consensual acts between peers. Physical abuse and sexual abuse are dichotomous variables while the others are continuous variables. Each type of abuse is examined separately in relation to the mother and the father, with the exception of the sexual abuse scale. In this study, the scores for the father and the mother were summed and averaged in order to obtain a total score for each 
scale. The CECA-Q showed high internal consistency for care scales, high test re-test reliability for all scales, and good convergent validity with an established measure of parental care (Bifulco, Bernazzani, Moran, \& Jacobs, 2005). It has been validated in both clinical (Smith, Lam, Bifulco \& Checkley, 2002) and community samples (Bifulco et al., 2005).

\section{Procedure:}

The study was presented to all students at schools who agreed to study participation and permission was obtained to use the mailing list of the university to invite potential participants. After giving their consent, students at schools were invited, depending on the agreements with school's principals, to log onto a secure website which contained the self-report questionnaires used in this study (RFQ-Y, PNI, BPFS-C and CECA-Q), or to complete paper-and-pencil versions of the questionnaires. The secure website included a description of the study, a consent page, and all questionnaires in a user-friendly online format. Each questionnaire was displayed on a unique webpage and proceeding to a subsequent questionnaire was permitted only once all questions in the current questionnaire had been answered. All items were in multiple-choice format. A percentage of participants received gifts cards, using a draw. Adolescents and young adults were informed that they could contact the team if they have any questions or concerns regarding the topics raised in the questionnaires.

\section{Analysis:}

As part of the exploratory analysis, using SPSS (version 23), a multivariate analysis of variance (MANOVA) was used to compare adolescent RF, pathological narcissisism and borderline personality traits between participants who had experienced sexual abuse and physical abuse and those who had not experienced those types of abuse. Correlation analysis was used to 
examine relationships between age, trauma, $\mathrm{RF}$, borderline personality traits and pathological narcissism.

Next, pathways from childhood trauma to borderline traits and pathological narcissism via RF were examined using a path analysis model in Mplus 7.12. (Muthén \& Muthén, 1998-2012). The model tested indirect effects, which involves calculation similar to mediation analysis. Effects tested started from the predictor (maltreatment) to the outcomes (borderline traits, grandiose narcissism and vulnerable narcissism) through adolescent RF scales as potential mediators. The model was tested using the maximum likelihood estimation method. All indirects effects were bootstrapped 1000 times in order to construct bias-corrected 95\% confidence intervals (CIs). The bootstrap procedure created 1000 random samples in replacement of the original sample to construct CIs. Indirect effects are considered significant at the .05 level when the $95 \%$ CI does not include the null value of 0 . Various fit indices were used to test the adequacy of the model : the Comparative Fit Index (CFI), the Tucker-Lewis Index (TLI), the root mean square error of approximation (RMSEA), the standardised root mean square (SRMR) et the chi-square. Guidelines suggest that values above .95 for the CFI and the TLI (Hoyle, 1995) as well as values below .05 for the RMSEA and the SRMR indicate an excellent fit. A nonstatiscally significant chi-square or ratio of chi-square to degrees of freedom less than 3 also indicate a good adjustment of the model (Browne \& Cudeck, 1992; Ullman, 2001).

\section{RESULTS}

\section{Preliminary analysis:}

Descriptive statistics are presented in table 1. Due to the small number of participants who reported experiencing physical abuse $(n=17)$ or sexual abuse $(n=16)$, adolescents and young 
adults who reported experiences of physical abuse and/or sexual abuse were grouped together to form a single group, sexual/physical abuse. This approach has been used previously in studies examining the abuse- related impacts (Kim, Cichetti, Rogosch, \& Manly, 2009). A MANOVA was used to compare adolescents with histories of sexual/physical abuse and adolescents without abuse histories and determine whether there were significant differences in RF, borderline personality traits, grandiose narcissism and vulnerable narcissism between them. The results of the MANOVA and the means and standard deviations for both groups are reported in table 2. Adolescents and young adults with histories of childhood sexual/physical abuse had significantly higher scores on both the uncertainty/confusion and excessive certainty scales of the RFQ-Y compared to adolescents with no histories of sexual/physical abuse. Adolescents in the sexual/physical abuse group also reported significantly more borderline traits as well as more grandiose and vulnerable narcissism.

\section{Relationships between variables:}

The results of correlational analyses with an alpha threshold of .05 are presented in table 3. Age was significantly and positively correlated to the interest/curiosity RFQ-Y scale. No other significant age difference was observed. The RFQ-Y uncertainty/confusion scale was positively and significantly associated with all types of abuse, borderline personality traits and both types of pathological narcissism. The RFQ-Y interest/curiosity scale was significantly and negatively correlated to borderline traits and neglect. Finally, the RFQ-Y excessive certainty was significantly and positively associated with grandiose narcissism and role reversal. Significant positive relationships were observed between all types of abuse and borderline traits, grandiose narcissism and vulnerable narcissism. This means that having experienced abuse or neglect is 
associated with more borderline personality traits, grandiose narcissism and vulnerable narcissism.

Given that the psychological abuse, antipathy and neglect CECA-Q scales were highly correlated, scores on these scales were aggregated into a composite score of emotional abuse. The scores of the three scales were standardized and summed to obtain the emotional abuse composite score. A similar procedure was previously used by Bottos and Nilsen (2014) and by Lumley and Harkness (2009), where a composite score of antipathy and neglect was used. The emotional abuse composite score was significantly associated with grandiose narcissism $(r=.29, p<.01)$, vulnerable narcissism $(r=.44, p<.01)$, borderline personality traits $(r=.40, p<.01)$, RFQ-Y uncertainty/confusion $(r=.30, p<.01)$ and RFQ-Y interest/curiosity $(r=-.15, p<.05)$. However, the relationship between emotional abuse and RFQ-Y excessive certainty was not significant $(r=.06, p>.05)$

\section{Path Analysis:}

A path analysis was conducted to test the hypothesis that adolescent RF mediated the relationship between childhood trauma (emotional abuse, sexual/physical abuse and role reversal) and pathological personality traits (borderline traits, grandiose narcissism and vulnerable narcissism $)$ in adolescence. All fit indices showed good to excellent model fit $(\mathrm{CFI}=1.00, \mathrm{TLI}=$ $1.00, \mathrm{RMSEA}<.001, \mathrm{SRMR}=.019$, and $\left.\chi^{2}(3)=2,789, p=.43, \chi^{2} / d f=.930\right)$. A visual depiction of the model is presented in Figure 1. Examination of covariance between the mediators and the outcomes variables revealed a weak and significant negative association between the confusion scale and the interest/curiosity scale of the RFQ-Y $(\beta=-.148 ; p=.046)$, but the excessive certainty scale did not have a significant effect on the other two RFQ-Y scales (p> .05). For the 
outcomes variables, a significant relationship was observed between borderline personality traits and grandiose narcissism $(\beta=.119 ; p=.015)$ as well as with vulnerable narcissism $(\beta=.238 ; p$ $<.01)$ and between the two phenotypes of narcissism $(\beta=.396 ; p<.01)$.

Results showed that emotional abuse had a direct effect on the uncertainty/confusion scale $(\beta=.182 ; p<.05)$ and the interest/curiosity scale $(\beta=-.197 ; p<.05)$ of the RFQ-Y. Moreover, emotional abuse $(\beta=.211 ; p<.01)$ and the RFQ-Y uncertainty/confusion scale $(\beta=.682 ; p<$ .01) had a direct effect on borderline personality traits. There was also a significant indirect effect of emotional abuse on borderline personality traits via the RFQ-Y uncertainty/confusion scale $(b=.160,95 \%$ IC $[.048,2,993])$, which accounted $37 \%$ of the total effect. The total effect of emotional abuse on adolescent borderline personality traits was reduced from $\beta=.335$ to a direct effect of $\beta=.211$. These results are consistent with partial mediation by RF (uncertainty/confusion) of the effect of childhood emotional abuse on borderline personality traits. The model explained $60,7 \%$ of the variance of adolescent borderline personality traits.

For vulnerable narcissism, there was a direct effect of emotional abuse $(\beta=.307 ; p<.01)$ and of sexual/physical abuse $(\beta=.098 ; p=.05)$ on adolescent vulnerable narcissism. A direct effect was also observed between RFQ-Y uncertainty/confusion scale $(\beta=.398 ; p<.01)$ and vulnerable narcissism. There was also a significant indirect effect between emotional abuse and vulnerable narcissism through RFQ-Y uncertainty/confusion scale $(b=.003,95 \%$ IC $[.004$, $0,067])$, the total effect of $\beta=.357$ between emotional abuse and vulnerable narcissism moving to a direct effect of $\beta=.307$. The indirect effect explained $14 \%$ of the total effect, which suggest a partial mediation by RF (uncertainty/confusion) of the relationship between emotional abuse and vulnerable narcissism. The model explained 33\% of the variance of vulnerable narcissism. 
Finally, there were significant direct effects of uncertainty/confusion $(\beta=.275 ; p<.01)$ and excessive certainty $(\beta=.225 ; p<.01)$ scales on adolescent grandiose narcissism. A direct effect was also observed between role reversal and RFQ-Y excessive certainty scale $(\beta=.16 ; p<$ $.05)$. However, direct effects of emotional abuse $(\beta=.117 ; p=.16)$ and role reversal $(\beta=.026 ; p$ $=.70$ ) on grandiose narcissism were not significant. With regard to indirect effects, there was a significant indirect effect of emotional abuse on grandiose narcissism through the RFQ-Y uncertainty/confusion $(b=.005,95 \%$ IC $[.004,0,111])$, which accounted for $38 \%$ of the total effect. The total effect of emotional abuse on grandiose narcissism was reduced from $\beta=.190$ to a non-significant direct effect of $\beta=.117$. Furthermore, the results showed a significant indirect effect of role reversal on grandiose narcissism via excessive certainty $(b=.002,95 \%$ IC $[.004$, 0,057]). The indirect effect explained $57 \%$ of the total effect which was reduced from $\beta=.061$ to a direct effect of $\beta=.026$.

\section{DISCUSSION}

The aim of the study was to examine associations between RF, childhood maltreatment, borderline personality traits, as well as vulnerable and grandiose narcissism in adolescents. A further aim was to investigate whether RF mediated the relationship between childhood maltreatment and personality disorder traits. Given the relative absence of data on the associations between different types of maltreatment, mentalizing and personality disorders in adolescents, we first examined these relationships. All types of emotional maltreatment (antipathy, negligence, psychological violence and role reversal) during childhood were significantly positively correlated with personality difficulties, as well as with mentalizing difficulties involving both uncertainty/confusion and excessive certainty regarding mental states of others. Furthermore, adolescents with histories of childhood sexual/physical abuse also 
reported significantly more BPD traits, more grandiose and vulnerable narcissism, and manifested more difficulties in mentalizing involving uncertainty/confusion regarding mental states, as well as more excessive certainty.

An important finding of the pathway analysis was that $61 \%$ of variance in BPD traits was explained by the effects of emotional abuse and mentalizing difficulties. Uncertainty/confusion about mental states partially mediated the relationship between emotional maltreatment and BPD traits, and $37 \%$ of the effect of emotional abuse on BPD traits was explained via the impact of emotional abuse on mentalizing. The cross-sectional nature of the study limits the extent to which causality can be inferred, but the findings suggest that the link between emotional maltreatment and BPD traits is partly explained through the negative consequences of family contexts on adolescents' mentalization, with this in turn having implications for BPD symptoms. This is consistent with a mentalizing model of BPD (Bateman \& Fonagy, 2010; Fonagy \& Luyten, 2009) where early experiences of adversity are considered to have a negative impact on the development of mentalizing which in turn is considered central to BPD. When children are treated as if they don't have minds, feelings and thoughts and where their psychological experience is disregarded by attachment figures, these intersubjective experiences undermines and harms their natural capacity to develop a robust sense of their own minds and consequently that of others. This is thought to contribute to vulnerability within the self and lack of adequate confidence in agentful mentalizing, manifesting in confusion when called upon to interpret affective reactions, increasing the risk of interpersonal difficulties when their perspective on psychological understanding of actions is lost and behavioral reactions are not linked to internal states. However, to date, only one previous study empirically demonstrated this by showing RF partially mediated the relationship between early adversity and BPD in adults (Chiesa \& Fonagy, 
2014). Our study appears to be the first study to replicate the finding that mentalizing mediates the relationship between early experiences of adversity and later BPD symptoms, showing that this mediation by mentalizing can also be observed in adolescents in the community. BPD traits in adolescents were found to be strongly positively correlated with their self-reported difficulties in mentalizing involving identification of mental states. One way of understanding this is that for adolescents who may be temperamentally more emotionally reactive and prone to intense negative affect, difficulties in mentalizing about self and others may increase the risk of affect dysregulation, especially in emotionally charged interpersonal interactions. Difficulties in having a sense what others are likely to feel and understand why they may be reacting in a particular way, as well as a lack of awareness of their own affect and the impact of this on others, likely contributes to the confusion and escalation of dysregulation in emotionally charged interpersonal interactions. This may underlie the interpersonal hypersensitivity observed in this group of individuals (Gunderson \& Lyons-Ruth, 2008). The relation between childhood histories of emotional maltreatment and adolescent BPD symptoms found in the present study is in line with previous work showing that poor theory of mind performance and maltreatment (physical and psychological abuse) before the age of 10 predicts BPD traits in preadolescence (Belsky et al., 2012). Emotional abuse, when attachment figures cause emotional dysregulation instead of helping children develop emotional regulation, may contribute to long term difficulties in affect regulation especially in adolescents genetically susceptible to developing BPD.

With regard to vulnerable narcissism, the findings show that there were direct effects of emotional abuse, as well as sexual/physical abuse on vulnerable narcissism in adolescents, and there was also a partial mediation of the relationship between emotional abuse and vulnerable narcissism through RFQ-Y uncertainty/confusion. The model explained 33\% of the variance in 
vulnerable narcissism, and mediation by RFQ-Y uncertainty/confusion accounted for $14 \%$ of the effect. This suggests that for vulnerable narcissism, pathways involving emotional abuse and mentalizing also applied, although it explains less variance than in BPD, where this pathway accounted for $61 \%$ of the variance.

With regard to grandiose narcissism, the findings show that the relationship between emotional abuse and grandiose narcissism was mediated by RFQ-Y uncertainty/confusion, and the relationship between role reversal and grandiose narcissism was mediated by RFQ-Y excessive certainty. Our findings suggest that emotional abuse and role reversal are risk factors for grandiose narcissism in adolescents. This extends previous research showing associations between a lack of warmth, empathy and support from parents during childhood and grandiose narcissism in adults and adolescents (Calvete, Orue, Gamez-Guadix \& Bushman, 2015; Trumpeter, Watson, O'Leary \& Weathington, 2008) as well as meta-analytic findings pointing to role reversal during childhood is a risk factor for personality disorders in adults (Hooper et al, 2011). The finding that mentalizing characterized by excessive certainty is associated with grandiose narcissism in adolescents is an important new contribution to the field that requires replication and warrants further research. It extends previous observations that narcissistic adults overestimate their ability to accurately identify the mental states of others (Ames et al., 2004; Ritter et al., 2011). Problematic mentalizing that we have characterized is excessively certainty can be considered a prementalizing mode and largely overlapping with psychic equivalence where there is a disregard of a number of mentalizing maxims such as the opacity of other minds, that mentalizing perspectives differ depending on the psychological experience of individuals, and that unlike physical reality that is no single mental reality, so that there is no such things as ultimate truth in mentalizing processes. Finally, the findings of the present study add to current 
knowledge by suggesting two pathways to grandiose narcissism. One path appears rooted in childhood emotional abuse which likely undermines the development of agentful appropriate and necessary basic confidence and trust in self and mentalizing, through intersubjective experiences where the psychological experience and mentalizing self is systematically attacked rather than mirrored, elaborated and developed. The other path appears to be linked to role reversal where excessive certainty and the illusion of knowing may be rewarded by parents needing the child to take charge, but where the child may lack few opportunities to learn to understand the limits of their mentalizing through interactions with adults. When children have to assume excessive parental responsibilities the illusion of knowing what others think and feel may facilitate a sense of mastery, control and knowing what to do. However, excessive certainty of this type may make individuals particularly prone to mentalizing errors where external cues such as facial expression are over interpreted without considering contextual cues that may help them to gain a better perspective of the complexity of the psychological experience of others.

This study has a number of strengths including the differentiation of different types of childhood abuse, the examination of different dimensions of mentalizing and relationships with different types of personality difficulties and the examination of all of this in one model. However the retrospective nature of the study limits the extent to which cause and effect can be inferred. Further research is required to determine whether our mediation findings can be shown in a longitudinal study regarding childhood abuse and neglect and the development of personality disorders in adolescence. In addition, the fact that we found these relationships in a community sample of adolescents and young adults suggests that the relations are robust even in a sample with a relatively limited number of individuals with severe abuse experiences compared to samples of at risk adolescents and those in the care of child protection services. Finally, further 
research is needed to examined gender differences and the fact that majority of participants were female may make the findings possibly less representative of male participants.

\section{Conclusion}

In line with the mentalizing model of psychopathology, the findings identify pathways involving metalizing difficulties characterized by uncertainty/confusion or excessive certainty as mediators of the relationships between childhood maltreatment experiences and adolescent BPD traits, as well as vulnerable and grandiose narcissism. Consistent with a mentalizing model of BPD, mentalizing difficulties were found to be particularly central in BPD.

Uncertainty/confusion about mental states partially mediated the relationship between emotional abuse and BPD traits, with the model explaining $61 \%$ of variance in BPD. Uncertainty/confusion about mental states also partially mediated the relation between emotional abuse and vulnerable narcissism, in addition to the significant effect of sexual/ physical abuse on vulnerable narcissism. The latter finding underscores the negative impact of childhood maltreatment on the development of healthy narcissism. Furthermore, excessive certainty about mental states fully mediated the relation between role reversal and grandiose narcissism, and uncertainty/confusion fully mediated the relation between emotional abuse and grandiose narcissism. These findings have important treatment implications and point to the importance of addressing mentalizing difficulties involving confusion and excessive certainty, as well as maltreatment, when intervening adolescents with personality pathology. 


\section{References}

Afifi, T. O., Mather, A., Boman, J., Fleisher, W., Enns, M. W., Macmillan, H., \& Sareen, J. (2011). Childhood adversity and personality disorders: results from a nationally representative population-based study. Journal of Psychiatric Research, 45, 814-822. doi: 10.1016/j.jpsychires.2010.11.008.

Ames, D. R., \& Kammrath, L. K. (2004). Mind-reading and metacognition: narcissism, not actual competence, predicts self-estimated ability. Journal of Nonverbal Behavior, 28, 187-209.

Bateman, A. \& Fonagy, P. (2010). Mentalization based treatment for borderline personality disorder. World Psychiatry, 9, 11-15. doi: 10.1002/j.2051-5545.2010.tb00255.x.

Battle, C. L., Shea, M. T., Johnson, D. M., Yen, S., Zlotnick, C., Zanarini, M. C., ... Morey, L.C. (2004). Childhood maltreatment associated with adult personality disorders: findings from the collaborative longitudinal personality disorders study. Journal of Personality Disorders, 18, 193-211.

Bégin, M., Ensink, K., Chabot, S., Normandin, L., \& Fonagy, P. (2017). Childhood maltreatment, adolescent psychological difficulties and borderline personality features: A personcentered approach. Adolescent Psychiatry (In press).

Bégin, M., Ensink, K., Kotiuga, J., Leclerc, C., Thériault-Sereno, A., \& Normandin, L. (2017). The borderline personality feature scale for children and adolescents; psychometric of the French version. Psychological Assessment (submitted). 
Belsky, D. W., Caspi, A., Arsenault, L., Bleidorn, W., Fonagy, P., Goodman, M., Houts, R., \& Moffit, T. E. (2012). Etiological features of borderline personality related characteristics in a birth cohort of 12-year-old children. Development and Psychopathology, 24, 251-265. doi: 10.1017/S0954579411000812.

Bifulco, A., Bernazzani, P. M., \& Jacobs, C. (2005). The childhood experience of care and abuse questionnaire (CECA.Q): Validation in a community series. British Journal of Clinical Psychology, 44, 563-581. doi:10.1348/014466505X35344.

Bifulco, A., Brown, G. W., \& Harris, T. O. (1994). Childhood experience of care and abuse (CECA): A retrospective interview measure. Journal of Child Psychology and Psychiatry, $35,1419-1435$.

Boone, D. (1998). Internal consistency reliability of the Personality Assessment Inventory with psychiatric inpatients. Journal of Clinical Psychology, 54, 839-843.

Bornovalova, M. A., Huibregtse, B. M., Hicks, B. M., Keyes, M., McGue, M., \& Iacono, W. (2013). Test of a direct effect of childhood abuse on adult borderline personality disorder traits: a longitudinal discordant twin design. Journal of Abnormal Psychology, 122, 180194. doi: $10.1037 / \mathrm{a} 0028328$.

Bottos, S., \& Nilsen, E. S. (2014). The cross-generational effects of maternal maltreatment histories: Implications for children's mentalizing development. Child Abuse \& Neglect, 38, 1094-1105. doi: 10.1016/j.chiabu.2014.02.012.

Bounoua, N., Felton, J. F., Long, K., Stadnik, R. D., Loya, J. M., MacPherson, L., \& Lejuez, C. W. (2015). Childhood emotional abuse and borderline personality features: The role of 
anxiety sensitivity among adolescents. Personal Mental Health, 9, 87-95. doi: 10.1002/pmh.1295.

Braehler, C., \& Schwannauer, M. (2012). Recovering an emerging self: exploring reflective function in recovery from adolescent-onset psychosis. Psychology and Psychotherapy, 85, 48-67. doi: 10.1111/j.2044-8341.2011.02018.x.

Browne, M. W., \& Cudeck, R. (1992). Alternative ways of assessing model fit. Sociological Methods \& Research, 21, 230-258. doi: 10.1177/0049124192021002005.

Brummelman, E., Thomaes, S., Nelemans, S. A., Orobio de Castro, B., Overbeek, G., \& Bushman, B. J. (2015). Origins of narcissism in children. Proceedings of the National Academy of Sciences, 112, 3659-3662. doi: 10.1073/pnas.1420870112.

Calvete, E., Orue, I., Gamez-Guadix, E., \& Bushman, B. J. (2015). Predictors of child-to-parent aggression: A 3-year longitudinal study. Developmental Psychology, 51, 663-676. doi: 10.1037/a0039092.

Chiesa, M. \& Fonagy, P. (2014). Reflective function as a mediator between childhood adversity, personality disorder and symptom distress. Personality and Mental Health, 8, 52-66. doi: 10.1002/pmh.1245.

Chrétien, S., Ensink, K., Descoteaux, J., \& Normandin, L. (2017). Measuring grandiose and vulnerable narcissism in adolescents. Assessment (submitted).

Cicchetti, D., Rogosch, F. A., Maughan, A., Toth, S. L. \& Bruce, J. (2003). False belief understanding in maltreated children. Development and Psychopathology, 15, 1067-1091. doi: 10.1017.S0954579403000440. 
Crick, N. R., Murray-Close, D., \& Woods, K. (2005). Borderline personality features in childhood: a short-term longitudinal study. Developmental Psychopathology, 17, 10511070. doi: 10.1017/S0954579405050492.

Cross, D., Fani, N., Powers, A., \& Bradley, B. (2017). Neurobiological development in the context of childhood trauma. Clinical Psychology: Science and Practice, 24, 111-124. doi: $10.1111 /$ cpsp.12198.

Crowell, S. E., Kaufman, E. A., \& Beauchaine, T. P (2014). A biosocial model of BPD: Theory and empirical evidence. In J. L. Tackett \& C. Sharp (eds.). Oxford handbook of suicide and self-injury. New York: Oxford University Press.

De Moor, M. H., Distel, M. A., Trull, T. J., \& Boosma, D. I. (2009). Assessment of borderline personality features in population samples: is the Personality Assessment InventoryBorderline Features scale measurement invariant across sex and age? Psychological Assesmment, 21, 125-130. doi: 10.1037/a0014502.

Dickinson, K. A., \& Pincus, A. L. (2003). Interpersonal analysis of grandiose and vulnerable narcissism. Journal of Personality Disorders, 17, 188-207.

Diguer, L., Turmel, V., Da Silva Luis, R., Mathieu, V., Marcous, L. A., \& Lapointe, T. (2014). Development and initial structure analysis of a french version of the pathological narcissism. European Psychiatry, 29. doi: 10.1016/S0924-9338(14)77997-0.

Duval, J., Ensink, K., Normandin, L., Sharp, C., \& Fonagy, P. (2018). Measuring reflective functioning in adolescents: Relations to personality disorders and psychological difficulties. Adolescent Psychiatry (In press). 
Ensink, K., Bégin, M., Normandin, L., \& Fonagy, P. (2016). Maternal and child reflective functioning in the context of child sexual abuse: pathways to depression and externalizing difficulties. European Journal of Psychotraumatology, 7, 30611. doi: 10.3402/ ejpt.v7.30611.

Ensink, K., Chrétien, S., Daigle, D., Normandin, L., Bégin, M., \& Fonagy, P. (2017). Pathological narcissism in adolescents: relationships with childhood maltreatment and internalizing and externalizing difficulties. Adolescent Psychiatry (In press).

Ensink, K., Normandin, L., Target, M., Fonagy, P., Sabourin, S., \& Berthelot, N. (2015). Mentalization in children and mothers in the context of trauma: An initial study of the validity of the Child Reflective Functioning Scale. British Journal of Developmental Psychology, 33, 203-217. doi: 10.1111/bjdp.12074.

Fonagy, P. (1999). Attachment, the development of the self, and its pathology in personality disorders. In Derksen, J., Maffei, C. \& Groen, H. (eds.) Treatment of personality disorders (p. 53-68). Dordrecht, Pays-Bas: Kluwer Academic Publishers.

Fonagy, P. \& Allison, E. (2014). The role of mentalizing and epistemic trust in the therapeutic relationship. Psychotherapy, 51, 372-380. doi: 10.1037/a0036505.

Fonagy, P., \& Bateman, A. W. (2007). Mentalizing and borderline personality disorder. Journal of Mental Health, 16, 83-101. doi: 10.1080/09638230601182045.

Fonagy, P., Gergely, G., Jurist, E. L. \& Target, M. (2002). Affect regulation, mentalization, and the development of the self. New York: Other Press. 
Fonagy, P., Leigh, T., Steele, M., Steele, H., Kennedy, R., Mattoon, G., ... Gerber, A. (1996).

The relation of attachment status, psychiatric classification, and response to psychotherapy. Journal of Consulting and Clinical Psychology, 64, 22-31.

Fonagy, P., \& Luyten, P. (2009). A developmental, mentalization-based approach to the understanding and treatment of borderline personality disorder. Developmental psychopathology, 21, 1355-1381. doi: 10.1017/S0954579409990198.

Gunderson, J. G., \& Lyons-Ruth, K. (2008). BPD's interpersonal hypersensitivity phenotype: a gene-environmental model. Journal of Personality Disorders, 22, 22-41. doi:10.1521/pedi.2008.22.1.22.

Ha, C., Sharp, C., Ensink, K., Fonagy, P. \& Cirino, P. (2013). The measurement of reflective function in adolescents with and without borderline traits. Journal of adolescence, 36, 1215-1223. doi: 10.1016/j.adolescence.2013.09.008.

Haxhe, S. (2016). Parentification and related processes: distinctions and implications for clinical practice. Journal of Family Psychotherapy, 27, 185-199. doi:

10.1080/08975353.2016.1199768.

Hooper, L. M., DeCoster, J., White, N., \& Voltz, M. L. (2011). Characterizing the magnitude of the relation between self-reported childhood parentification and adult psychopathology. Journal of Clinical Psychology, 67, 1028-1043. doi: 10.1002/jclp.20807.

Hoyle, R.H. (1995). The structural equation modeling approach: Basic concepts and fundamental issues. In R. H. Hoyle (ed.), Structural equation modeling: Concepts, issues, and applications (p. 1-15). Thousand Oaks, CA: Sage. 
Jones, R. A., \& Wells, M. (1996). An empirical study of parentification and personality. The American Journal of Family Therapy, 24, 145-152. doi: 10.1080/01926189608251027.

Jovev, M., McKenzie, T., Whittle, S., Simmons, J. G., Allen, N. B., \& Chanen, A. M. (2013). Temperament and maltreatement in the emergence of borderline and antisocial personality pathology during early adolescence. Journal of Canadian Academy of Child and Adolescent Psychiatry, 22, 220-230.

Joyce, P. R., McKenzie, J. M., Luty, S. E., Mulder, R. T., Carter, J. D., Sullivan, P. F., \& Cloninger, C. R. (2003). Temperament, childhood environment and psychopathology as risks factors for avoidant and borderline personality disorders. Australian and New Zealand Journal of Psychiatry, 37, 756-764.

Kim, J., Cichetti, D., Rogosch, F. A., \& Manly, J. T. (2009). Child maltreatment and trajectories of personality and behavioral functioning: Implications for the development of personality disorder. Development and Psychopathology, 21, 889-912. doi: 10.1017/S0954579409000480.

Koizumi, M., \& Takagishi, H. (2014). The relationship between child maltreatment and emotion recognition. PLOS ONE, 9, e86093. doi: 10.1371/journal.pone.0086093.

Lumley, M., \& Harkness, K. (2009). Childhood maltreatment and depressotypic cognitive organization. Cognitive Therapy and Research, 33, 511-522. doi: 10.1007/s10608-0099257-7. 
Mechanic, K. L., \& Barry, C. T. (2015). Adolescent grandiose and vulnerable narcissism: association with perceived parenting practices. Journal of Child and Family Studies, 24, 1510-1518. doi: 10.1007/s10826-014-9956-X.

Ménard, K. S., \& Pincus, A. L. (2014). Child maltreatment, personality pathology, and stalking victimization among male and female college students. Violence and Victims, 29, 300316. doi: 10.1891/0886-6708.VV-D-12-00098R1.

Michonski, J. D., Sharp, C., Steinberg, L., \& Zanarini, M. C. (2013). An item response theory analysis of the DSM-IV borderline personality disorder criteria in population-based sample of 11- to 12-year-old children. Personality Disorders, 4, 15-22. doi: 10.1037/a0027948.

Miller, J. D., Dir, A., Gentile, B., Wilson, L., Pryor, L. R., \& Campbell, W. K. (2010). Searching for a vulnerable dark triad: Comparing factor 2 psychopathy, vulnerable narcissism, and borderline personality disorder. Journal of Personality, 78, 1529-1564. doi: 10.1111/ j.1467-6494.2010.00660.x.

Miller, J. D., Hoffman, B. J., Gaughan, E. T., Gentile, B., Maples, J., \& Campbell, W. K. (2011). Grandiose and vulnerable narcissism: a nomological network analysis. Journal of Personality, 79, 1013-1042. doi: 10.1111/j.1467-6494.2010.00711.x.

Miller, A. L., Muehlenkamp, J. J. \& Jacobson, C. M. (2008). Fact or fiction: diagnosing borderline personality disorder in adolescents. Clinical Psychology Review, 28, 969-981. doi: 10.1016/j.cpr.2008.02.004. 
Morey, L. C. (1991). Personality Assessment Inventory - Professional Manual. Florida, USA: Psychological Assessment Resources, Inc.

Muthén, L.K., \& Muthén, B.O. (1998-2012). Mplus Version 7 user's guide. Los Angeles, CA: Muthén \& Muthén.

O'Reilly, J. \& Peterson, C. C. (2015). Maltreatment and advanced theory of mind development in school-aged children. Journal of Family Violence, 30, 93-102. doi: 10.1007/s10896-0149647-9.

Pears, K. C. \& Fisher, P. A. (2005). Emotion understanding and theory of mind among maltreated children in foster care: Evidence of deficits. Development and Psychopathology, 17, 47-65. doi: 10.10170S0954579405050030.

Pincus, A. L., Ansell, E. B., Pimentel, C. A., Cain, N. M., Wright, A. G. C., \& Levy, K. N. (2009). Initial construction and validation of the Pathological Narcissism Inventory. Psychological Assessment, 21, 365-379. doi: 10.1037/a0016530.

Pollak, S. D., Cicchetti, D., Hornung, K. \& Reed, A. (2000). Recognizing emotions in faces: Developmental effects of child abuse and neglect. Developmental psychology, 36, 679688. doi: 10.1037//0012-1649.36.5.679.

Ritter, K., Dziobek, I., Preibler, S., Rüter, A., Vater, A., Fydrich, T., ... Roepke, S. (2011). Lack of empathy in patients with narcissistic personality disorder. Psychiatric Research, 187, 241-247. doi: 10.1016/j.psychres.2010.09.013.

Sansone, R. A., Hahn, H. S., Dittoe, N., \& Wiederman, M. W. (2011). The relationship between childhood trauma and borderline personality symptomatology in a consecutive sample of 
cardiac stress patients. International Journal of Psychiatry in Clinical Practice, 15, 275279. doi: $10.3109 / 13651501.2011 .593263$.

Shenk, C. E., Putnam, F. W., \& Noll, J. G. (2013). Predicting the accuracy of facial affect recognition: The interaction of child maltreatment and intellectual functioning. Journal of Experimental Child Psychology, 114, 229-242. doi: 10.1016/j.jecp.2012.08.007.

Slavin-Mulford, J., Sinclair, S. J., Stein, M., Malone, J., Bello, I., \& Blais, M. A. (2012). External validity of the Personality Assessment Inventory (PAI) in a clinical sample. Journal of Personality Assessment, 94, 593-600. doi: 10.1080/00223891.2012.681817.

Smith, N., Lam, D., Bifulco, A., \& Checkley, S. (2002). Childhood Experience of Care and Abuse Questionnaire (CECA.Q). Validation of a screening instrument for childhood adversity in clinical populations. Social Psychiatry and Psychiatric Epidemiology, 37, 572579. doi:10.1007/s00127-002-0589-9

Stein, M. B., Pinsker-Apen, J. H., \& Hilsenroth, M. J. (2007). Borderline pathology and the Personality Assessment Inventory (PAI): an evaluation of criterion and concurrent validity. Journal of Personality Assessment, 88, 81-90. doi: 10.1080/ 00223890709336838 .

Stepp, S. D., Whalen, D. J., Scott, L. N., Zalewski, M., Loeber, R., \& Hipwell, A. E. (2014). Reciprocal effects of parenting and borderline personality disorder symptoms in adolescent girls. Development and Psychopathology, 26, 361-378. doi: 10.1017/ S0954579413001041.

Taubner, S., White, L. O., Zimmermann, J., Fonagy, P., \& Nolte, T. (2013). Attachment-related mentalization moderates the relationship between psychopathic traits and proactive 
aggression in adolescence. Journal of Abnormal Child Psychology, 41, 929-938. doi:10.1007/s10802-013-9736-X

Trumpeter, N. N., Watson, P. J., O’Leary, B. J., \& Weathington, B. L. (2008). Self-functioning and perceived parental empathy and love consistency with narcissism, depression, and self-esteem. The Journal of Genetic Psychology, 169, 51-71. doi: 10.3200/GNTP.169.1.51-71.

Ullman, S. E. (2001). Structural equation modeling. Dans B. G. Tabachnick \& L. S. Fidell (ed.), Using multivariate statistics ( $4^{\text {th }}$ edition, p. 966). Needham Heights, MA: Allyn and Bacon.

Widow, C. S., Czaja, S. J., \& Paris, J. (2009). A prospective investigation of borderline personality disorder in abused and neglected children followed up into adulthood. Journal of Personality Disorders, 23, 433-446. doi: 10.1521/pedi.2009.23.5.433.

Wright, A. G. C., Lukowitsky, M. R., Pincus, A. L., \& Conroy, D. A. (2010). The higher order factor structure and gender invariance of the Pathological Narcissism Inventory. Assessment, 17, 467-483. doi: 10.1177/1073191110373227.

Zelkowitz, P., Paris, J., Guzder, J., \& Feldman, R. (2001). Diatheses and stressors in borderline pathology of childhood: the role of neuropsychological risk and trauma. Journal of the American Academy of Child and Adolescent Psychiatry, 40, 100-105. doi: 10.1097/ 00004583-200101000-00022. 
Table 1

Descriptive statistics of the sample

\begin{tabular}{lcccc}
\hline Variable & $\mathrm{N}$ & Mean $(\mathrm{SD})$ & Minimum & Maximum \\
\hline Age & 263 & $17,5(2,98)$ & 12 & 21 \\
RFQ-Y uncertainty & 219 & $2,97(1,01)$ & 1 & 5,90 \\
RFQ-Y interest & 220 & $4,61(0,65)$ & 2,25 & 6 \\
RFQ-Y certainty & 217 & $3,46(0,86)$ & 1,17 & 6 \\
BPFS-C (total) & 262 & $54,79(14,66)$ & 26 & 99 \\
Antipathy & 263 & $13,64(4,72)$ & 8 & 33 \\
Neglect & 263 & $13,27(4,52)$ & 8 & 28,50 \\
Psychological abuse & 263 & $3,72(4,75)$ & 0 & 23,50 \\
Role reversal & 263 & $35,83(9,54)$ & 21 & 74 \\
PNI grandiose & 204 & $3,19(0.63)$ & 1,38 & 5,08 \\
PNI vulnérable & 204 & $3,22(0.83)$ & 1,15 & 5,23 \\
\hline
\end{tabular}

Note. RFQ-Y : Reflective Function Questionnaire for Youth, BPFS-C (total) = Bordeline Personality Features Scale for Children, total, PNI :

Pathological Narcissism Inventory. The Antipathy, Neglect, Psychological abuse and Role reversal scale are measured with the Childhood

Experiences of Care and Abuse Questionnaire. 
Table 2

Group comparisons (sexual/physical abuse vs control) for $R F$, borderline personality traits and pathological narcissism

\begin{tabular}{llccc}
\hline Variables & Group & M & SD & $F$ \\
\hline RFQ-Y uncertainty/confusion & Sexual/physical & 3.84 & 1.02 & $21.55^{* *}$ \\
& Control & 2.88 & 0.91 & \\
RFQ-Y interest/curiosity & Sexual/physical & 4.70 & 0.78 & 0.30 \\
& Control & 4.62 & 0.66 & \\
RFQ-Y excessive certainty & Sexual/physical & 3.84 & 1.00 & $4.78^{*}$ \\
& Control & 3.42 & 0.85 & \multirow{2}{*}{ Borderline traits } \\
Sulnerable narcissism & Control & 65.65 & 13.52 & $12.40^{* *}$ \\
& Sexual/physical & 3.85 & 14.49 & \multirow{2}{*}{$16.23^{* *}$} \\
Grandiose narcissism & Control & 3.14 & 0.70 & \\
& Sexual/physical & 3.57 & .53 & $8.74 * *$ \\
\hline
\end{tabular}

Note $: * * p<.01, * p<.05$.

RFQ : Reflective Function Questionnaire for Youth, $\mathrm{M}=$ mean, $\mathrm{SD}=$ standard deviation, Sexual/physical = experiences of sexual and/or physical abuse. 


\section{Table 3}

Correlations between $R F$, maltreatment, borderline personality traits and pathological narcissism.

\begin{tabular}{|c|c|c|c|c|c|c|c|c|c|c|c|}
\hline & $\widehat{A} g e$ & Uncertainty & $\mathrm{I} / \mathrm{C}$ & Certainty & Antipathy & Neglect & $\begin{array}{c}\text { Psycho } \\
\text { abuse }\end{array}$ & $\mathrm{R} / \mathrm{R}$ & $\begin{array}{l}\text { PNI } \\
\text { vuln } \\
\end{array}$ & $\begin{array}{c}\text { PNI } \\
\text { grand }\end{array}$ & $\begin{array}{l}\mathrm{BPD} \\
\text { traits } \\
\end{array}$ \\
\hline Age & - & - & - & - & - & - & - & - & - & - & - \\
\hline Uncertainty & -.04 & - & - & - & - & - & - & - & - & - & - \\
\hline $\mathrm{I} / \mathrm{C}$ & $.27 * *$ & $-.18 * *$ & - & - & - & - & - & - & - & - & - \\
\hline Certainty & -.04 & .07 & $.15^{*}$ & - & - & - & - & - & - & - & - \\
\hline Antipathy & .09 & $.30 * *$ & -.13 & .08 & - & - & - & - & - & - & - \\
\hline Neglect & .06 & $.18 * *$ & $-.14 *$ & -.04 & $.71 * *$ & - & - & - & - & - & - \\
\hline Psycho abuse & .09 & $.29 * *$ & -.10 & .12 & $.62 * *$ & $.39 * *$ & - & - & - & - & - \\
\hline $\mathrm{R} / \mathrm{R}$ & -.07 & $.26 * *$ & .04 & $.16^{*}$ & $.30 * *$ & $.26 * *$ & $.46^{* *}$ & - & - & - & - \\
\hline PNI vuln. & .11 & $.51 * *$ & -.04 & .01 & $.47 * *$ & $.36^{* *}$ & $.28 * *$ & $.18^{* *}$ & - & - & - \\
\hline PNI grand. & .05 & $.38 * *$ & -.09 & $.28 *$ & $.28 * *$ & $.22 * *$ & $.22 * *$ & $.22 * *$ & $.63 * *$ & - & - \\
\hline BPD traits & .09 & $.76 * *$ & $-.23 * *$ & .07 & $.42 * *$ & $.27 * *$ & $.30 * *$ & $.23 * *$ & $.66 * *$ & $.43 * *$ & - \\
\hline
\end{tabular}

** $p<.01, * p<.05$

Abbreviations: RFQ-Y = Reflective Functioning Questionnaire for Youth, $\mathrm{I} / \mathrm{C}=\mathrm{RFQ}-\mathrm{Y}$ interest/curiosity scale, Certainty $=\mathrm{RFQ}-\mathrm{Y}$ excessive certainty scale, Psycho abuse $=$ psychological abuse, R/R $=$ role reversal, PNI $=$ Pathological Narcissism Inventory, grand $=$ grandiose narcissism, vuln $=$ vulnerable narcissism, BPD traits $=$ borderline personality traits. 
Table 4.

Parameter estimates of the covariances between maltreatment, RF, borderline personality traits, grandiose narcissism and vulnerable narcissism in 263 adolescents

\begin{tabular}{|c|c|c|c|c|}
\hline & Estimations & ES & $P$ & $R^{2}$ \\
\hline Uncertainty regressed on : & & & & .122 \\
\hline Emotional abuse & .182 & .086 & $.034^{*}$ & \\
\hline Sexual/physical Abuse & .155 & .084 & .065 & \\
\hline Role reversal & .134 & .086 & .074 & \\
\hline Interest/Curiosity regressed on : & & & & .035 \\
\hline Emotional abuse & -.197 & .096 & $.039 *$ & \\
\hline Sexual/physical abuse & .053 & .078 & .498 & \\
\hline Role reversal & .107 & .076 & .155 & \\
\hline Excessice certainty regressed on: & & & & .038 \\
\hline Emotional abuse & -.048 & .090 & .595 & \\
\hline Sexual/physical abuse & .123 & .077 & .110 & \\
\hline Role reversal & .156 & .069 & $.024 *$ & \\
\hline BPD traits regressed on: & & & & .607 \\
\hline Emotional abuse & .211 & .063 & $.001 *$ & \\
\hline Sexual/physical abuse & -.026 & .048 & .593 & \\
\hline Role reversal & -.010 & .052 & .844 & \\
\hline RFQ-Y uncertainty & .682 & .050 & $.000^{*}$ & \\
\hline RFQ-Y interest/curiosity & -.091 & .054 & .096 & \\
\hline RFQ-Y excessive certainty & .024 & .046 & .601 & \\
\hline Vuln. narcissism regressed on: & & & & .330 \\
\hline Emotional abuse & .307 & .069 & $.000 *$ & \\
\hline Physical/sexual abuse & .098 & .051 & $.050 *$ & \\
\hline Role reversal & -.071 & .057 & .211 & \\
\hline RFQ-Y uncertainty & .398 & .067 & $.000 *$ & \\
\hline RFQ-Y interest/curiosity & .030 & .075 & .685 & \\
\hline RFQ-Y excessive certainty & -.033 & .058 & .565 & \\
\hline Grand. narcissism regressed on: & & & & .222 \\
\hline Emotional abuse & .117 & .084 & .164 & \\
\hline Sexual/physical Abuse & .041 & .053 & .430 & \\
\hline Role reversal & .026 & .068 & .703 & \\
\hline RFQ-Y uncertainty & .275 & .068 & $.000 *$ & \\
\hline RFQ-Y interest/curiosity & -.009 & .081 & .908 & \\
\hline RFQ-Y excessive certainty & .225 & .059 & $.000 *$ & \\
\hline
\end{tabular}

$* p<.05$.

Note. BPD traits = Borderline personality disorder traits, ; RFQ-Y, Reflective Function Questionnaire for Youth. 


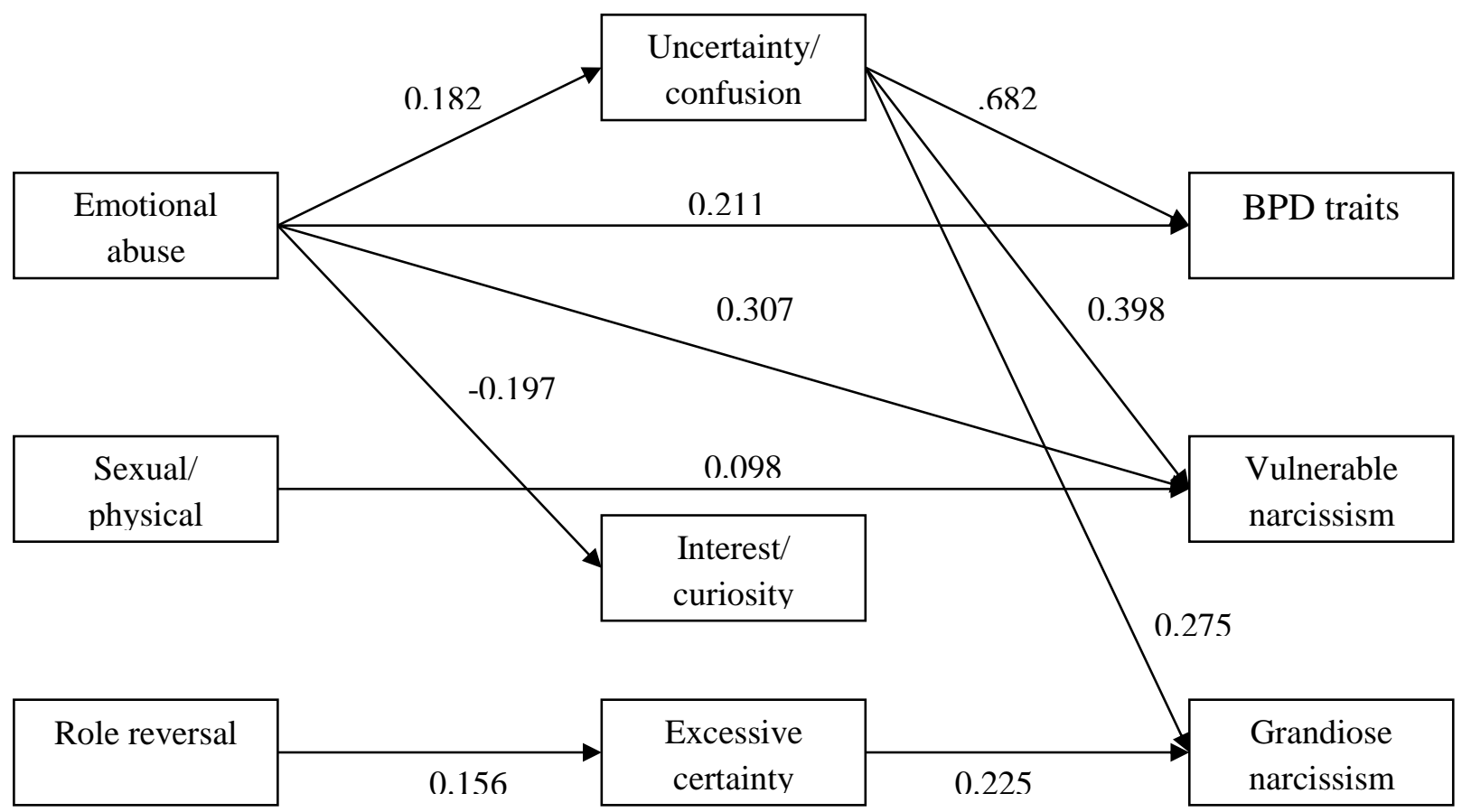

Figure 1. Path analysis describing the significant associations between maltreatment (emotional abuse, sexual/physical abuse and role reversal), adolescent RF (Uncertainty/confusion, interest/curiosity and excessice certainty scales) and borderline personality traits and pathological narcissism (vulnerable and grandiose) in 263 adolescents. Parameters are standardized.

Note. In order to simplify the visual depiction of the model, non-significant relations and covariances were omitted here. 